\title{
Analysis of Change of Physical Properties of Organic Repair Products due to Fire Exposition
}

\author{
Menéndez, Esperanza ${ }^{1}$, Imamoto, Kei-ichi ${ }^{2}$, Gettu, Ravindra ${ }^{3}$, Noguchi, Takafumi ${ }^{4}$ and \\ Recino Hairon ${ }^{1}$
}

\author{
${ }^{1}$ Institute Eduardo Torroja of Construction Science, Spanish National Research Council (IETcc- \\ CSIC), Serrano Galvache street 4, 28033-Madrid, Spain, emm@ietcc.csic.es \\ ${ }^{2}$ Tokyo University of Science, Faculty of Engineering, Department of Architecture, 113-8656- \\ Tokyo, Japan, imamoto@rs.kagu.tus.ac.jp \\ ${ }^{3}$ Indian Institute of Technology Madras, Department of Civil Engineering, Alumni Ave, 600036- \\ Chennai, Tamil Nadu, India, gettu@iitm.ac.in \\ ${ }^{4}$ Tokyo University, Faculty of Engineering and Graduate School of Engineering, 7-3-1 Hongo, \\ Bunkyo-ku, 113-8656 Tokyo, Japan, noguchi@bme.arch.t.u-tokyo.ac.jp
}

\begin{abstract}
Organic repair products for concrete can be exposed to accidental incidents, like fire. The increase of temperature produces a modification in some of their properties. In general, these types of repair products have organic fibers to increase their tixotropic properties, but they are more sensible to the high temperature than the Portland cement or aggregates. In order to analyze the behavior of organic repair mortars with temperature three types of repair mortars are studied. These repair products have the organic components composed by acetate fiber of polyvinyl like Vinyl Acetate Acrylate (VAA), Copolymer of Vinyl Acetate Vinyl Versatate (VeoVA) and Acrylic polymers fibres. The repair products are tested increasing the temperature from $1.7^{\circ} \mathrm{C} /$ min until $200^{\circ} \mathrm{C}, 400^{\circ} \mathrm{C}$ or $600^{\circ} \mathrm{Crespectively}$ during 20 minutes. After that, the samples are cooled in four different cooling conditions two of them slow and two others fast, and with and without oxygen. These conditions are used in order to simulate the different conditions that can occur during the cooling after fire. After the testing the visual aspect, the color and brightness and the open porosity is analyzed in each condition of test. In this work the relationship between the temperature of exposition, the cooling conditions and the change in some physical properties are studied.
\end{abstract}

Keywords: Organic Repair Mortar, Fire Resistance Test, Color Change, Open Porosity.

\section{Introduction}

The progression of the temperatures in the interior of the fire area is greatly conditioned by a series of very varied parameters, such as the type and density of the fire, the capacity for thermal dispersion of the epidermis, the level and disposition of the ventilation, etc. Kucera, P. (2007). Although it is possible to model or predict the thermal evolution of the gas in the affected area to a greater or lesser degree during the project, and from there and design sufficiently safe structures (with viable criteria for its use). The evaluation of the residual capacity of existing structures affected by a fire usually require a more realistic determination of the distribution of the temperatures in the different elements of the structure, Kodur, V.K.R. and Phan, L. (2007). It must be borne in mind that the real conditions of the fire (strength of the fire, ventilation, etc.) are difficult to determine precisely and a theoretical prediction not contrasted with real data 
could give rise to significant deviations in areas relative to the thermal analysis of the structure and hence the mechanical evaluation.

The distribution of the temperatures in the interior of the area affected by the fire is not homogeneous, which is why the determination of the number of testing points, their distribution, etc., so that the results are representative and constitute a sound basis for the structural analysis is a relevant question. However, when samples taken from a real fire are analysed it is not always possible to have the suitable number or disposition samples available.

On the other hand, in order to determine the residual resistant capacity of the elements of the structural concrete affected by the fire, it is important to find out not only the distribution of the temperatures in the elements, but also how the effect on other relevant mechanical properties come about from exposure to fire, such as the steel-concrete adhesion. Within the series of temperatures that are produced in the interior of the section, there is an important significance from the mechanical point of view, as are $500^{\circ} \mathrm{C}$. On the one hand, the average value of the resistance to compression losses of the concrete (with lime aggregate) contemplated at a regulatory level is in the order of $40 \%$, which would correspond approximately to the admissible loss in a residential or administrative building in a strict reinforced position (EN1992 - Eurocode 2: Design of concrete Structures). It is the basis for one of the most used simplified calculation methods in the verification of concrete structures in the case of fire, which is known as the simplified $500^{\circ} \mathrm{C}$ isothermal method, Ashely, E. (2007).

The cement based materials have a low thermal conductivity and an elevated specific heat, which is why ambient temperature constitutes a suitable protection for the reinforcement. However, when it becon thermal transformations cement. From $300^{\circ} \mathrm{C}$ gel, which brings abou exceed $900^{\circ} \mathrm{C}$ in order to bring about a compl

the portlandite comes about at between $450-550^{\circ} \mathrm{C}$, as does a loss of $\mathrm{CO}_{2}$ of the carbonates
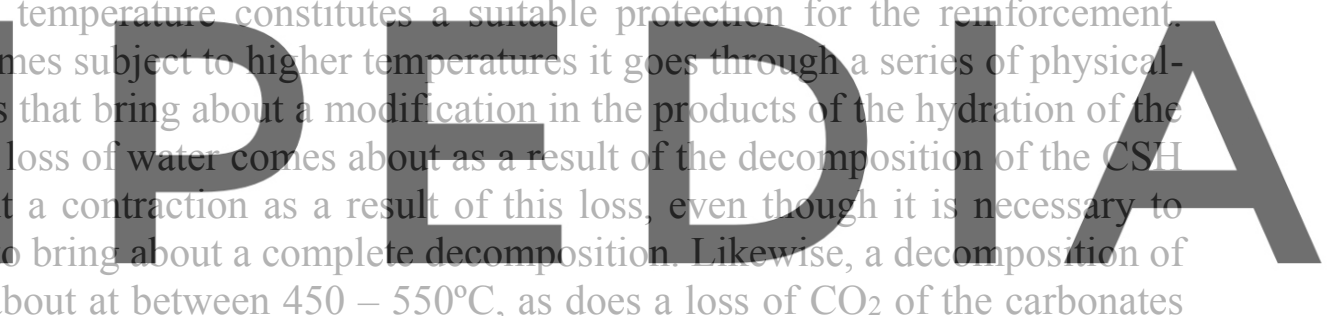

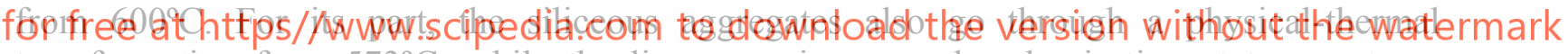
transformation from $573^{\circ} \mathrm{C}$, while the lime experiences a decarbonisation at temperatures greater than $600^{\circ} \mathrm{C}$. Although it is important to indicate the possible changes in the aggregate as an effect of the temperature, it also depends on other factors such as size, porosity permeability, etc. - the less porous the aggregate, the less susceptible it is to the action of the fire, Charreau, G.L., Luna, F. (2000). The decomposition of portlandite in cement based materials can be used as an indicator of progression of temperature inside of the material and situate the isotherm 500 in the material, Menéndez, E., Vega, L. (2012).

The physical-thermal transformations undergone by the concrete as an effect of the temperature are translated into a loss of performance, especially when the material exceeds $600^{\circ} \mathrm{C}$. As the temperature increases, a modification in the creep comes about, which can also be seen as a strong dependency on its resistance and elasticity, Schneider, U. (1976). On the other hand, the conditions of putting out the fire must be taken into account, as the speed of cooling or the contact with the water has a significant influence on the physical-mechanical conditions present in the concrete once the fire is extinguished, Nassil, A. (2006). Specifically, the physical-thermal transformations that the components of the concrete go through serve to characterise it after it has been subject to the fire Colombo, M. and Felicetti, R. (2007). In this case, X-ray diffraction, thermal analysis and scanning electron microscopy techniques have 
been used with the aim of analysing the behaviour of the concrete exposed to a real fire. Some of these instrumental techniques, such as thermal analysis, are usually used to study the behaviour of certain materials when exposed to the action of fire and high temperatures. As a rule, the fundamental objective of these analyses is to look at the possible improvements that could come about through the use of certain materials that could substitute or complement others, Zhong, H., Wei, P., Jiang, P. and Wang, G. (2006).

Polymer-modified mortar (PCM) contains synthetic resins and/or combustible polymers such as rubber. Hence, the combustibility of PCM is strongly affected by the type and amount of combustible polymer, S. Akihama, et.al (1973). The combustible properties of several types of PCMs at high temperatures can be tested using JIS A 1321 (a testing method for incombustibility of internal finish material and procedure of buildings), Y. Oham, S. Suzuki and H. Ozawa (1980). The influence of a polymer admixture on the fire resistance of PCC and analysis of peeling and explosion of PCMs by fire tests are carried out Chandra, S., Berntsson, L., and Anderberg, Y. (1980). On the other hand, the incombustibility of polymer-modified mortars is strongly affected by the polymer type rather than the polymer-cement ratio or polymer content. Some authors have been performed tests about heat release of PCMs Ohama, Y., Shirai, A., and Imamoto, K. (2011).

In the present work, studies of different polymer-modified mortars have been done. The repair mortars have exposed at $200^{\circ} \mathrm{C}, 400^{\circ} \mathrm{C}$ and $600^{\circ} \mathrm{C}$ during 20 minutes and are cooling quickly or slowly. The visual aspect, open porosity and colorimetry is analysed in the different samples tested to takeconclusions on their behaviour at different temperatures.
2 Raw Materials
Repair mortars were in
suppliers, characteristic
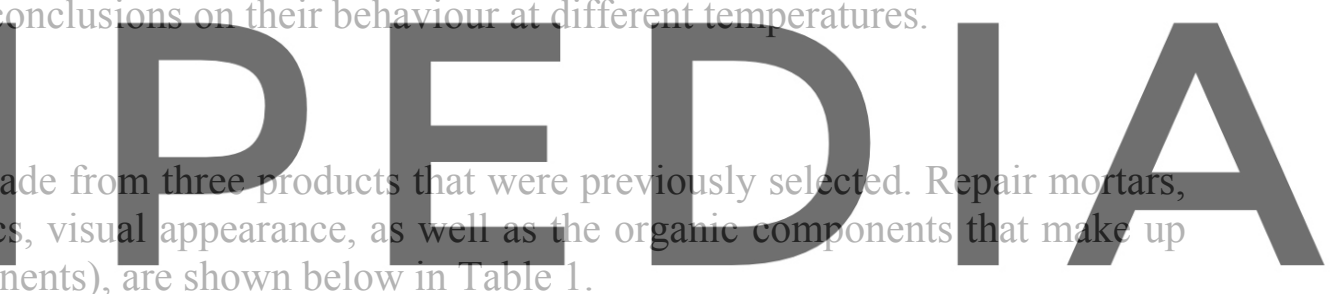

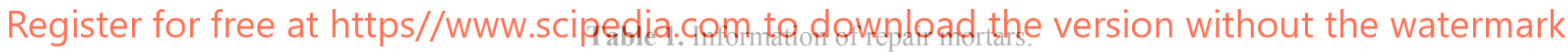

\begin{tabular}{|c|c|c|c|}
\hline Product & Codification & Type of polymer & $\begin{array}{c}\text { Visual } \\
\text { Aspect }\end{array}$ \\
\hline PLANITOP HDM MAXI & PHM & Acrylic polymer & \\
\hline $\begin{array}{c}\text { MAPEGROUT EASY } \\
\text { FLOW GF }\end{array}$ & MEF & $\begin{array}{c}\text { Copolymer of Vinyl Acetate Vinyl Versatate } \\
\text { (VeoVA) }\end{array}$ & \\
\hline $\begin{array}{c}\text { MASTER EMACO } \\
\text { S 5400 }\end{array}$ & S5400 & Vinyl Acetate Acrylate (VAA) & \\
\hline
\end{tabular}

\section{Manufacturing, Curing Process of Repair Mortars and Test Procedure}

Repair mortars were manufactured following the procedure described in the manufacturer's instructions, the mixture is kneaded, poured into the molds and the specimens are cured at $20^{\circ}$ $\mathrm{C}$ and $60 \%$ humidity. Next, in Figure 1, the general appearance of the cured specimens is shown. Samples were tested at temperatures of $200^{\circ} \mathrm{C}, 400^{\circ} \mathrm{C}$ and $600^{\circ} \mathrm{C}$. The exposure time as well as the thermal gradient of the test is shown in Figure 2 below. Four samples of each product 
were tested, two in the presence of oxygen and another two in the absence of oxygen respectively. The cooling conditions are shown below:

- Slow cooling: Condition that allows the sample to cool inside the oven until it reaches room temperature $\left(20^{\circ} \mathrm{C}\right)$.

- Fast cooling: Condition that consists of suddenly removing the sample from the oven, so that it loses temperature quickly, while the sample is reserved in a desiccator.

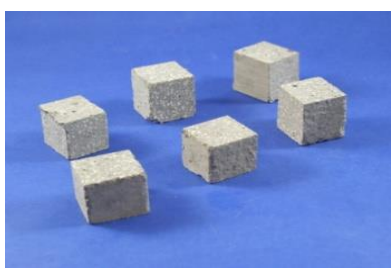

Figure 1. Visual Aspect of the repair mortar.

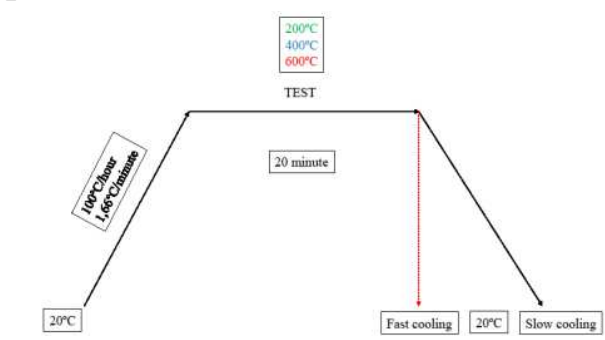

Figure 2. Heating curve proposed for the test

\section{Porosity Accessible to Water}

The porosity of the mortars that have been made with the repair products is determined. For this, the porosity of samples that have not been subjected to heat treatment (reference) is determined, and the porosity of the samples subjected to the fire resistance test is determined.

Procedure that allows to study the behavior of the porosity as the test conditions change.

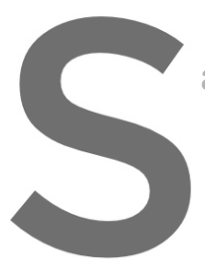

The methodology accessible to water. N
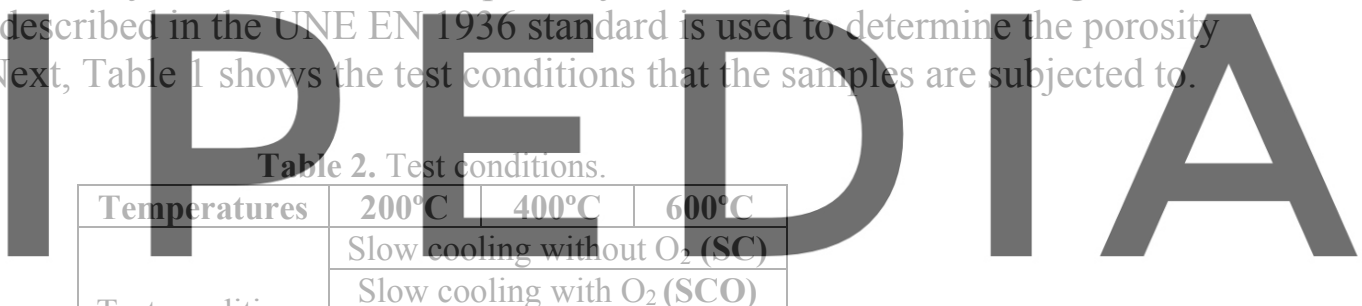

\begin{tabular}{l|l}
\multirow{2}{*}{ Test conditions } & Slow cooling with $\mathrm{O}_{2}(\mathrm{SCO})$
\end{tabular}

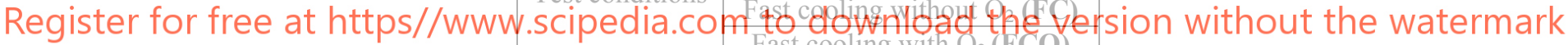

\subsection{Porosity of Mortars as a Function of the Product Used}

Next, Figures 3 shows the porosity values obtained from this test are plotted. Some dispersion in the porosity values is observed for each of the mortars tested. Porosity increases as the test temperature increases; the apparent increasing of cracking in mortars can causes this effect. 


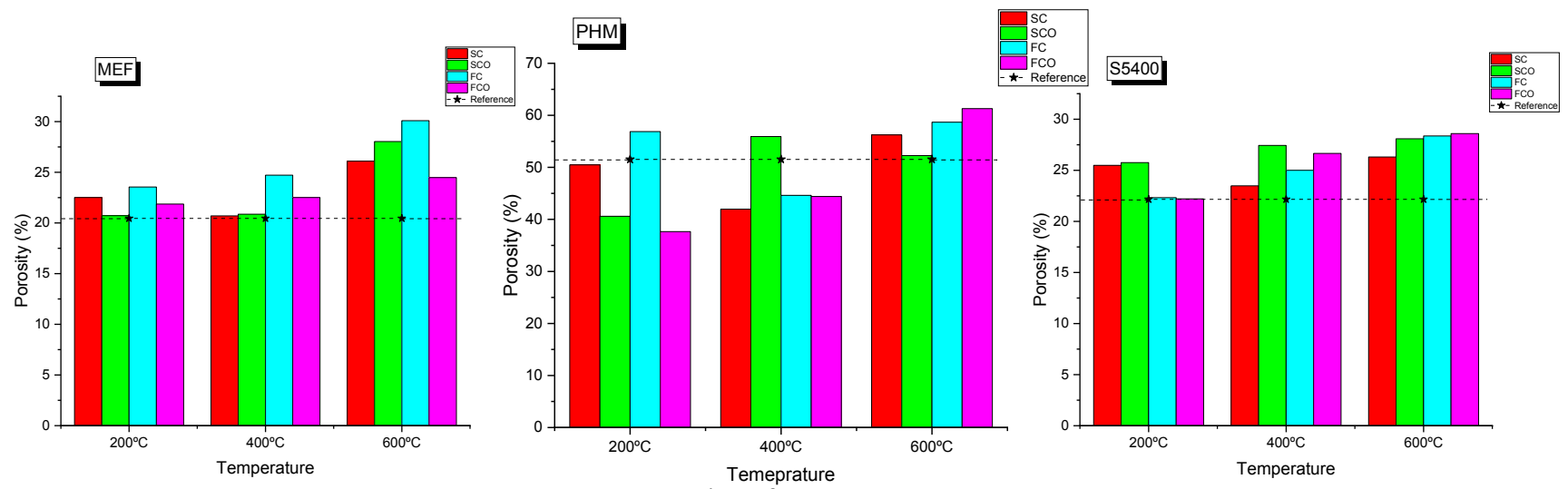

Figure 3. Porosity of mortars.

\subsection{Porosity Variation as Function of the Test Temperature}

\section{In order to study the behavior of the products tested, at each test temperature, the variation of the porosity as a function of the study temperature is shown below (Figures 4).}

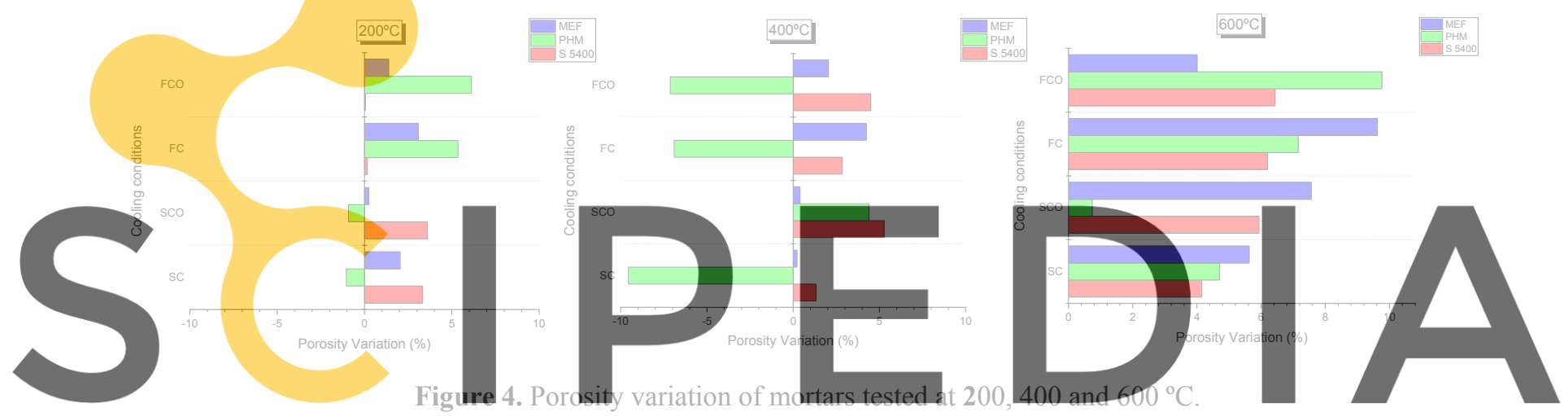

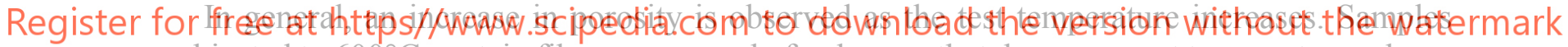
subjected to $600^{\circ} \mathrm{C}$ contain fibers composed of polymers that decompose at temperatures above $500^{\circ} \mathrm{C}$, forming gases such as methane, carbon dioxide and carbon monoxide among others. These gases increase the pressure inside the mortar, causing tensions in the areas where the pressure is higher, this effect can cause cracking, increasing the porosity of the mortar.

On the other hand, a decrease in the porosity in the PHM mortar is observed, at $400^{\circ} \mathrm{C}$, caused by the fusion and diffusion of the fibers through the pores, filling the air pores, an effect that would explain this behavior.

\subsection{Porosity Variation as Function of the Cooling Conditions}

The increment of the porosity is shown depending on the test condition, it should be noted that the values shown below are values that reflect the increase in porosity with respect to the reference porosity values for each mortar tested. In any case, the most favorable scenario (least increase in porosity) is in which the mortar tested is cooled slowly. Although between the two scenarios in which it cools slowly, the one performed without oxygen shows less increase in porosity.
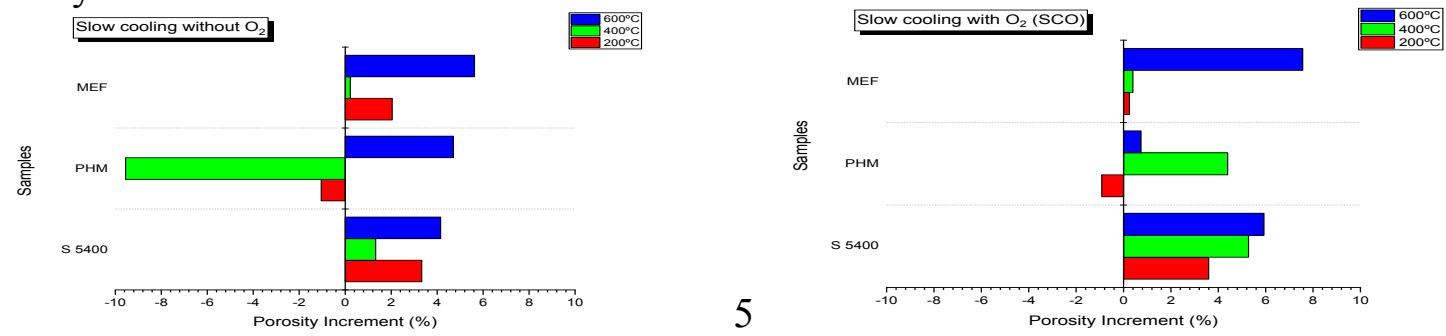
Figure 5. Porosity increment of mortars that were cooled slowly with and without $\mathrm{O}_{2}$.
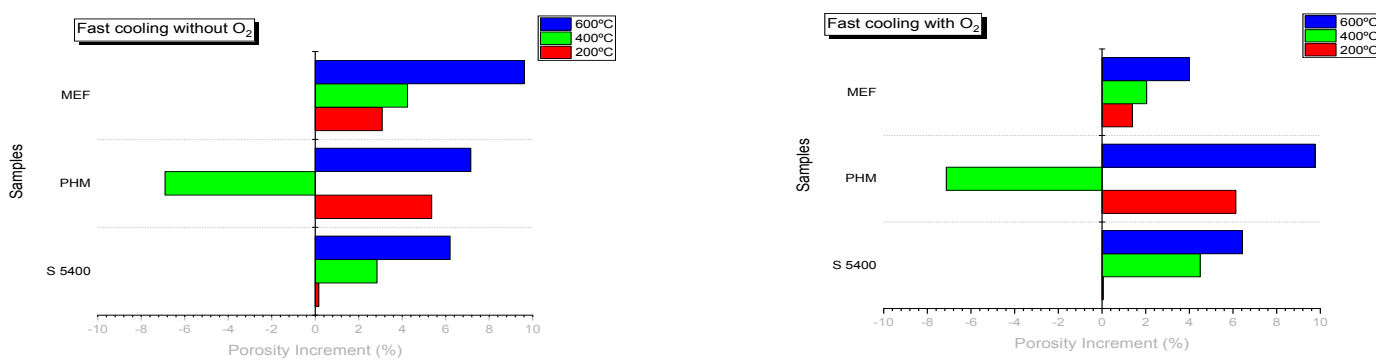

Figure 6. Porosity increment of mortars that were cooled suddenly with and without $\mathrm{O}_{2}$.

\section{Colorimetry}

Colorimetric techniques are based on the measurement of radiation absorption in the visible area by colored substances. All systems that quantify color from three variables have colorimetric aspects: Luminance, Length and Purity.

\section{With this technique,} in the mortars that have
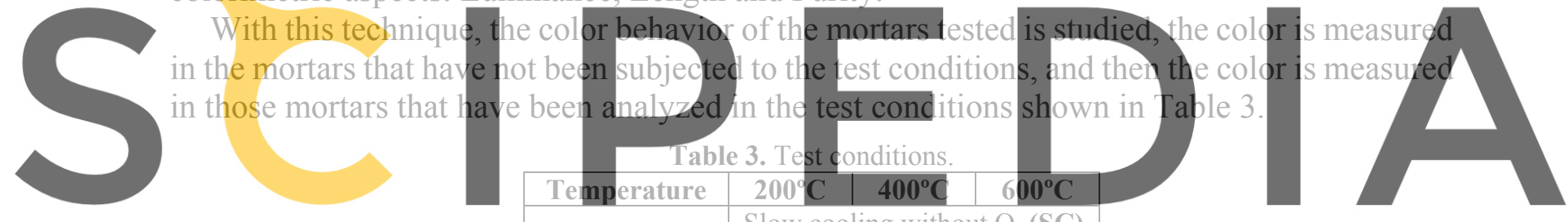

Slow cooling with $\mathrm{O}(\mathrm{SCO})$

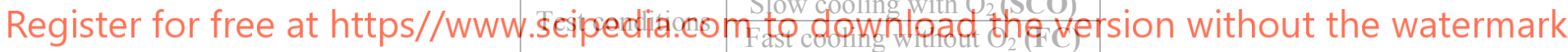
Fast cooling with $\mathrm{O}_{2}$ (FCO)

\subsection{Colorimetric Variation as Function of Test Temperature}

Next, a data processing is carried out. The color variation of the tested products is determined, compared with the color tones of the reference (product without heat treatment).

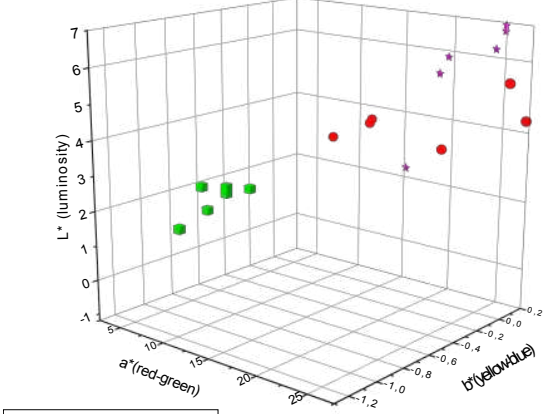

Color variation at $400^{\circ} \mathrm{C}$
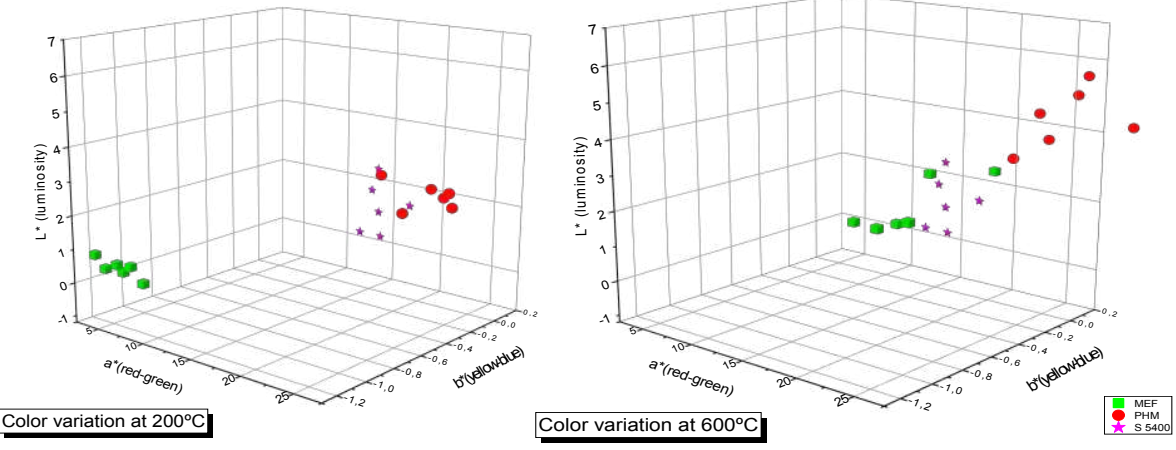

Color variation at $600^{\circ} \mathrm{C}$

Figure 7. Color variation of the mortars tested at 200,400 and $600^{\circ} \mathrm{C}$.

At $200^{\circ} \mathrm{C}$ and $400^{\circ} \mathrm{C}$, it is observed that the MEF product does not show variation around the 
reference colorimetric values. As for the temperature of $600^{\circ} \mathrm{C}$, the color variation of the products tested show a linear trend around the blue color when the brightness increases.

\section{Conclusions}

The following conclusions are obtained from the tests performed:

- The repair mortar that has the lowest porosity is MEF; on the other hand, the product that has the highest porosity is the PHM.

- In temperatures, at $200^{\circ} \mathrm{C}$ and at $400^{\circ} \mathrm{C}$ a good behavior is observed in the materials tested, while at $600^{\circ} \mathrm{C}$ the behavior is very unfavorable in all cases, because at $600^{\circ} \mathrm{C}$, the increase in porosity is significant and it can cause reduction of mechanical strength. On the other hand, the PHM mortar is the one that shows the highest porosity, but it is the only one in which the porosity decreases when tested at temperatures between $200^{\circ} \mathrm{C}-400^{\circ} \mathrm{C}$. This behavior may be caused by the composition of the fibers. The melting temperature of fibers is in the range $200^{\circ} \mathrm{C}-400^{\circ} \mathrm{C}$, causing diffusion of the fibers through the pores of the cementitious paste, filling capillary pores, and decreasing the porosity.

In general, a linearity is observed between the increase in temperature and the decrease in brightness, approaching darker tones as the test temperature increases.

\section{Acknowledgements}

E. Menéndez would like to express their gratitude to the funding of the project CSIC 201460 E067 Analysis of

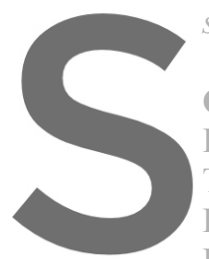

systems of diagnosis, decision

ORCID

Esperanza Menéndez: http

Takafumi Noguchi: https

Kei-ichi Imamoto: https:

Hairon Recino: https://orcidorg/0000-0002-4831-7790
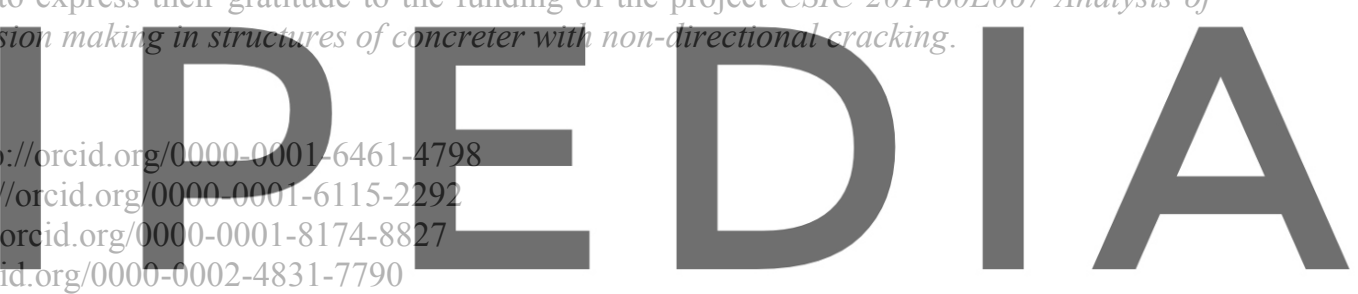

Register for free at https//www.scipedia.com to download the version without the watermark References

Ashely, E. (2007). The Role of Performance-Based Design in Concrete Fire Resistance. Fire Resistance of Concrete Structures. Concrete in Focus, Fall.

Background document on parametric temperature-time curves according to Annex A of prEN1991-1-2. Profil Arbed. (2001). Centre de recherches. CEN/TC250/SC1/N298A. Document No EC1-1-2/72.

Chandra, S., Berntsson, L. and Anderberg, Y. (1980). Some Effects of Polymer Addition on the Fire Resistance of Concrete, Cement and Concrete Research, V.10, No.3, pp.367-375.

Charreau, G.L. and Luna, F. (2000). Efecto del fuego sobre los hormigones. Alteraciones sufridas por los agregados. Instituto Nacional de Tecnología Industrial. INTI - CECON. Jornadas de Desarrollo e Innovación.

Colombo, M. and Felicetti, R. (2007). New NDT techniques for the assessment of fire-damaged concrete structures. Fire Safety Journal, 42, pp. 461-472.

Concrete Masonry Fire Resistance.(2005). Northwest Concrete Masonry Association. Tek note.

Design of concrete structures for fire resistance. (1981). Bulletin d'information $\mathrm{n}^{\circ} 145$. Comite eurointernational du beton.

Documento Básico DB-SI: Seguridad en caso de incendio.(2005). Código Técnico de la Edificación. Ministerio de Vivienda - Gobierno de España. 
EN-1992 - Eurocode 2 (1992). Design of concrete Structures - Part 1.2: General rules - Structural fire design.

Ercolani, G.D., Ortega, N.F. and Señas, L. (2007). Empleo de Ultrasonidos y Esclerometría en el diagnóstico de estructuras de hormigón afectadas por elevadas temperatura. Asociación Argentina de Ensayos no Destructivos y Estructurales. IV Conferencia Panamericana de END. Buenos Aires.

Fletcher, I.A., Welch, S., Torero, J.L., Carvel, R.O. and Usmani, A. (2007). Behaviour of Concrete Structures in Fire. Thermal Science, 11, no.2, pp. 37-52.

Hajpál, M. Monuments Exposed to Fire or High Temperature. Fire Technology, 38, 2002, pp. 373-382.

K. Kishitani, et.al. (1982). A study on fire resistance of polymer-modified mortar, Summaries of technical papers of annual meeting Architectural Institute of Japan, pp.169-170.

Kodur, V.K.R. and Phan, L. (2007). Critical factors governing the fire performance of high strength concrete systems. Fire Safety Journal, 42, pp. 482-488

Kucera, P. (2007). Thermal-mechanical Analysis of Concrete Structure Exposed to High Temperature. Except from the Proceedings of the COMSOL Users Conference. Grenoble.

Lottman, B.B.G. (2007). Fire in bored tunnels. Structural behavior, during fire conditions, of bored tunnels made with a concrete segmental lining. Delf University of Technology. Netherlands.

Mehta, P.K. (1986). Concrete. Structure, properties and materials. Ed. Prentice-Hall, Inc. USA.

Menéndez, E. and Vega, L. (2012). Use of decomposition of portlandite in concrete fire as indicator of temperature progression into the material. JTAC, Vol. 110, N. 1. DOI:10.1007/s10973-011-2159-4

Menéndez, E. and Vega, L. Study of dehydration and rehydration processes of portlandite in mature and young cement pastes. JTAC, Vol. 110, N. 1. DOI:10.1007/s10973-011-2167-4

Menéndez, E. and Vega, L. (2010). Analysis of the behaviour of the structural concrete after the fire at the Windsord Buildin

Nassil, A. (2006). Postfir 323-332.

Ohama, Y., Shirai, A., and Imamoto, K. (2011) Mortars Using Redispe Construction, Czarneck is
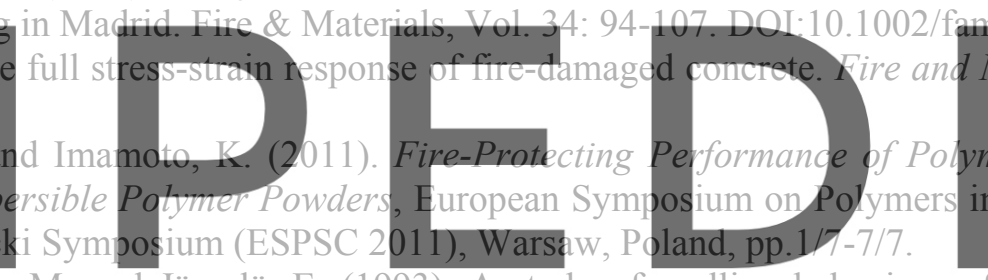

Sarvaranta, L., Elomaam, M. and Järvelä, E. (1993). A study of spalling behaviour of PAN fibrereinforced concrete by thermal analysis. Fire and Materials, 17: 225-230. Fire and Materials, 1: 103-115.

Shirai, A., Ohama, Y. and Kokubun, Y. (2009). Fire-Protecting Performance of Polymer-Modified Mortars for Buildings, Proceedings of the 6th Asian Symposium on Polymers in Concrete, Shanghai, China, pp.507-513.

S. Akihama, et.al. (1973). A Study on shear wall using polymer-modified mortar ( Part. 2) Mechanical properties, heat and fire resistance of concrete, Kajima Technical Research Report, Vol.21, pp.565-574.

Taylor, H.F.W. (1997). Cement Chemistry. Ed. Thomas Telford. USA.

UNE-EN-1991- Eurocódigo 1. (1991). Acciones en las estructuras. Parte 1-2: Acciones en estructuras expuestas al fuego.

Y. Ohama, Y. Kokubun and A. Shirai. (2008). Fire-protecting performance of polymer-modified mortar for buildings and proposal for fire-protecting performance test methods for them. J. Struc. Constr. Eng. AIJ, Vol.73, No.631, 1449-1457.

Y. Ohama, S. Suzuki and H. Ozawa. (1980). Incombustibility of polymer-modified mortar, Proceeding of JCI 2nd Conference, pp.253-256.

Zhong, H., Wei, P., Jiang, P. and Wang, G. (2006). Thermal degradation behaviours and flame retardancy of $\mathrm{PC} / \mathrm{ABS}$ with novel silicon-containing flame retardant. Fire and Materials, 31: 411423. 